\title{
Histological studies on the retina and cerebellum of Wistar rats treated with Arteether ${ }^{\mathrm{TM}}$
}

\author{
Okunlola, AI. ${ }^{1}$, Okunlola, CK. ${ }^{1}$, Okani, CO. ${ }^{2}$, Adewole, OS. ${ }^{3 *}$, Ofusori, DA. ${ }^{3}$, \\ Komolafe, OA. ${ }^{3}$, Ojo, SK. ${ }^{3}$, Bejide, RA. ${ }^{4}$, Ayoka, AO. ${ }^{5}$ and Ojewole, JAO. ${ }^{6}$

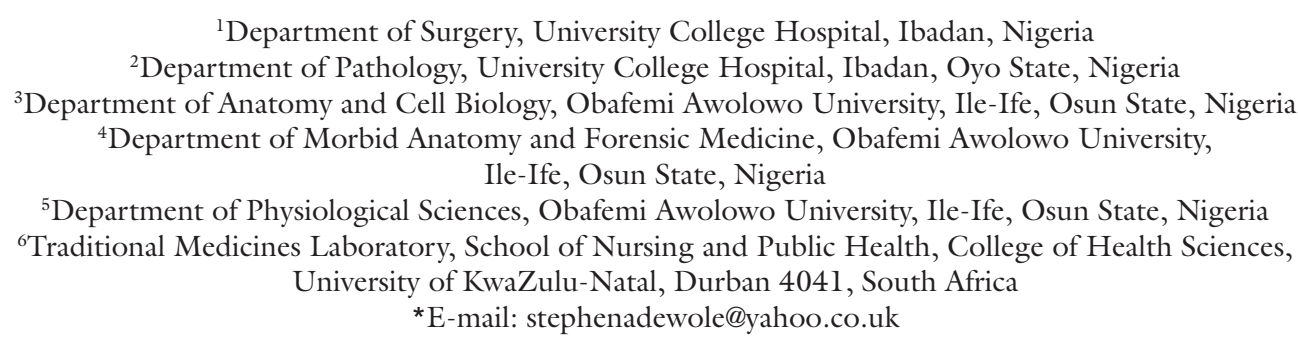

\begin{abstract}
Introduction: Arteether ${ }^{\mathrm{TM}}$, a derivative of artemisinin, is among the recent drugs that have given renewed hope for combating malarial menace. The present study investigated the effects of arteether ${ }^{\mathrm{TM}}$ on the histology of the retina and cerebellum of Wistar rats. Materials and Methods: Twenty adult albino Wistar rats weighing 150-200 g, were randomly divided into four groups (A, B, C and D) of five animals each and used for this study. Group A rats were given intramuscular (i.m.) arteether ${ }^{\mathrm{TM}}(3 \mathrm{mg} / \mathrm{kg}$ b.w.) daily for 3 days. Group B rats were given i.m. arteether ${ }^{\mathrm{TM}}(6 \mathrm{mg} / \mathrm{kg}$ b.w. $)$ daily for 3 days. Group C rats were also given i. m. of arteether ${ }^{\mathrm{TM}}$ ( $3 \mathrm{mg} / \mathrm{kg} \mathrm{b.} \mathrm{w.)} \mathrm{daily} \mathrm{for} 3$ days, and the same dose was repeated at two-weekly intervals for 4 further weeks; while Group D rats which received normal saline $(0.9 \% \mathrm{w} / \mathrm{v}, 3 \mathrm{ml} / \mathrm{kg}$ b.w. $)$, served as controls. At the end of the experiment, the rats were sacrificed by cervical dislocation. The retina and cerebellum were excised and processed routinely for histopathology changes, using haematoxylin and eosin stain (H \& E), as well as Nissl stain. Results: Results obtained showed normal cellular components of the retina and cerebellum in all groups, and no cyto-pathological changes were observed. Conclusion: Thus, this study showed that under light microscopic examination, therapeutic doses of arteether ${ }^{\mathrm{TM}}$ caused no significant cyto-pathologic changes in the retina and cerebellum of Wistar rats.
\end{abstract}

Keywords: Arteether ${ }^{\mathrm{TM}}$, malaria, retina, cerebellum, histology, Wistar rats.

\section{Introduction}

Malaria is a leading cause of mortality and morbidity in developing countries of the world, and remains a major public health problem in endemic regions (BREMAN, ALILIO and MILLS, 2004). In the face of resistance to chloroquine by Plasmodium falciparum, the malaria parasite responsible for about 2 million annual deaths from malaria, artemisinin and its derivatives (artesunate, artemether ${ }^{\mathrm{TM}}$, arteether ${ }^{\mathrm{TM}}$ and dihydroartemisinin) have given renewed hope for combating resistant malaria (HIEN, 1994; HARINASUTA and KARBWANG, 1994). Treatment of severe malaria relies on the use of artemisinin-derived agents (VALECHA and TRIPATH, 1997; VAN AGTMAEL, EGGELTE and VAN BOXTEL, 1999). These drugs have gained considerable prominence in the chemotherapy of both uncomplicated and severe malaria by demonstrating high activity against multidrug-resistant falciparum strains with low toxicity profiles (CHANTHAP, TSUYUOKA, NABANGCHANG et al., 2005).

Studies on artemisinin derivatives have shown evidence of toxicity on the brainstem (GENOVESE, NEWMAN and BREWER, 2000; NONTPRASERT, PUKRITTAYAKAMEE, DONDORP et al., 2002), superior colliculus (EWEKA and ADJENE, 2008a), stomach
(EWEKA and ADJENE, 2008b), and testis (IZUNYA, NWAOPARA, AIGBIREM et al., 2010). Neurotoxicity in experimental animals has been speculated to be associated particularly with the use of intramuscular injections of artemether $^{\mathrm{TM}}$ or arteether ${ }^{\mathrm{TM}}$ (BREWER, PEGGINS, GRATE et al., 1994). Signs and symptoms of neurotoxicity have been noted, including ataxia, nystagmus and dizziness, which mimic cerebella lesion.

Therefore, there is a need to investigate the nature and severity, if any, of histological changes in the retina and cerebellum, as there is paucity of such studies in biomedical literature.

\section{Materials and Methods}

\subsection{Animal management}

Twenty healthy albino Wistar rats (Rattus norvegicus) of both sexes, weighing between $100 \mathrm{~g}$ and $120 \mathrm{~g}$ were obtained from the Department of Anatomy, Ladoke Akintola University of Technology, Ogbomoso, Oyo State, Nigeria, and used for the study. There was a pre-experimental period of four weeks during which time the animals acclimatized 

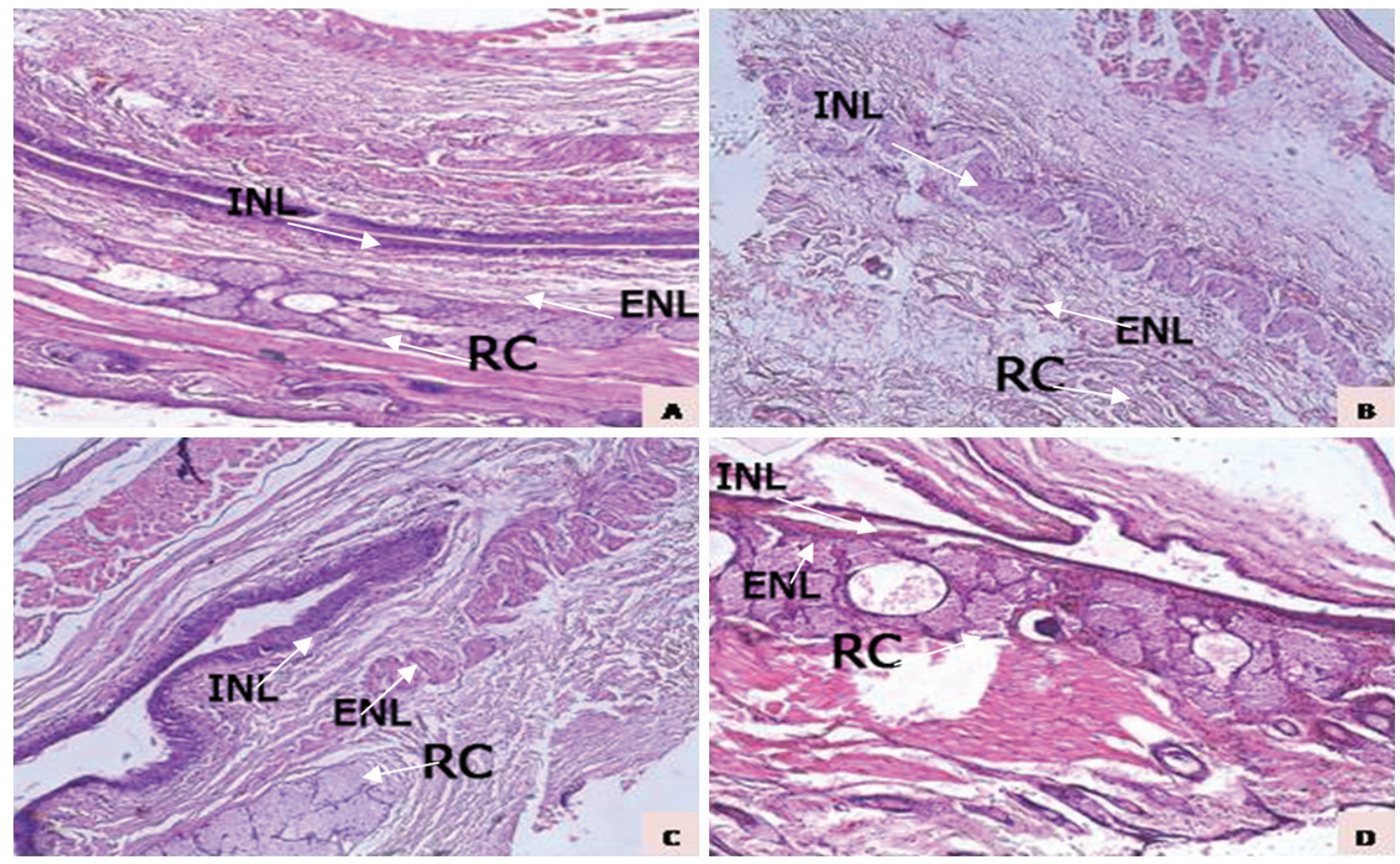

Figure 1. Light Photomicrographs of the retina of Groups A, B, C and D rats. H\&E x100. RC- Rods and Cones; ENL- External nuclear layer; INL- Internal nuclear layer.

and were maintained on standard rat chow and given tap water ad libitum before the commencement of our experiments. The weights of the rats increased to 150 $200 \mathrm{~g}$ before the commencement of our experiments. The animals were randomly assigned into four groups A, B, C, and $\mathrm{D}$ of five rats each. Each group of rats was kept in a separate cage under natural light and dark cycles at room temperature. They were maintained on standard rat chow and drinking tap water given ad libitum. Group A rats were given intramuscular (i.m.) arteether ${ }^{\mathrm{TM}} 3 \mathrm{mg} / \mathrm{kg} \mathrm{b}$. w. daily for 3 days. Group B rats were given $6 \mathrm{mg} / \mathrm{kg} \mathrm{b}$. w. i.m. arteether $^{\mathrm{TM}}$ for 3 days. Group C rats were given $3 \mathrm{mg} / \mathrm{kg}$ b. w. arteether ${ }^{\mathrm{TM}}$ for 3 days, and the same dose was repeated at two-weekly intervals, making 3 consecutive treatments. Group D rats were given equivalent volume of normal saline for three days. The rats received humane care according to the criteria outlined in the "Guide for the Care and Use of Laboratory Animals" prepared by the National Academy of Sciences and published by the National Institutes of Health.

\subsection{Histological studies}

At the end of our experimental period, the animals were examined for general physical activity, mobility and agility. Thereafter, they were sacrificed by cervical dislocation. The organs of interest in this study (i.e., the eyes and cerebellum), were excised and fixed in $10 \%$ formol saline for 48 hours for histological studies. The tissues were routinely processed for paraffin wax embedding. Thereafter, $6 \mu \mathrm{m}$ thick paraffin cross sections containing eyes and cerebellar tissues were mounted on slides and stained using routine $\mathrm{H}$ and E (DRURY and WALLINGTON, 1980), and Nissl substance staining (Cresyl Echt Violet) method. The stained sections were examined under a Leica research microscope (DM 750) with a digital camera attached (Leica ICC 50), and digital photomicrographs of stained sections were taken.

\section{Results}

\subsection{Physical examination of the animals}

The animals were apparently healthy during the period of acclimatization. There was no significant change in the physical appearance and activities of the four groups of the animals during the experimental period. At the end of the experiment, all animals in the animal groups were apparently healthy, and they were physically active.

\subsection{Histopathological findings}

The cellular components of the retina are organized in well-defined layers in all groups of the animals, as seen in photomicrographs of the sections through the retina of the Wistar rats (Figures 1, 2). No pathological lesions were detected in the retina of all the animals.

Photomicrographs of the cerebellum of the Wistar rats (Figures 3,4) showed the three distinct layers of the adult cerebellar cortex. No cyto-pathological changes were noted.

\section{Discussion}

The findings of this study indicate that Arteether ${ }^{\mathrm{TM}}$ does not induce any cyto-pathological change in the retina and cerebellum of Wistar rats. Artemisinin and its derivatives are 


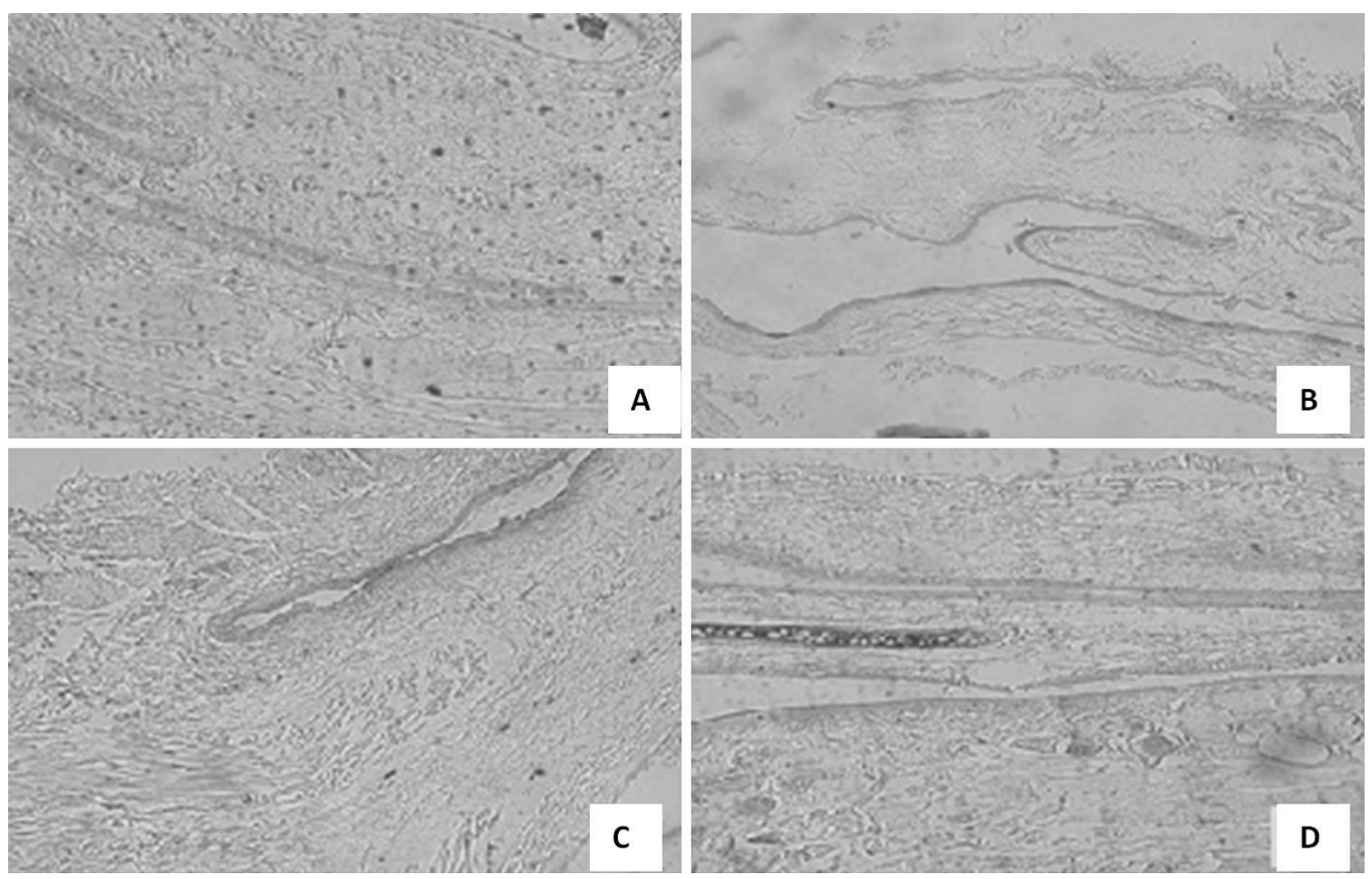

Figure 2. Light Photomicrographs of the retina of Groups A, B, C and D rats. Nissil Stain x100.
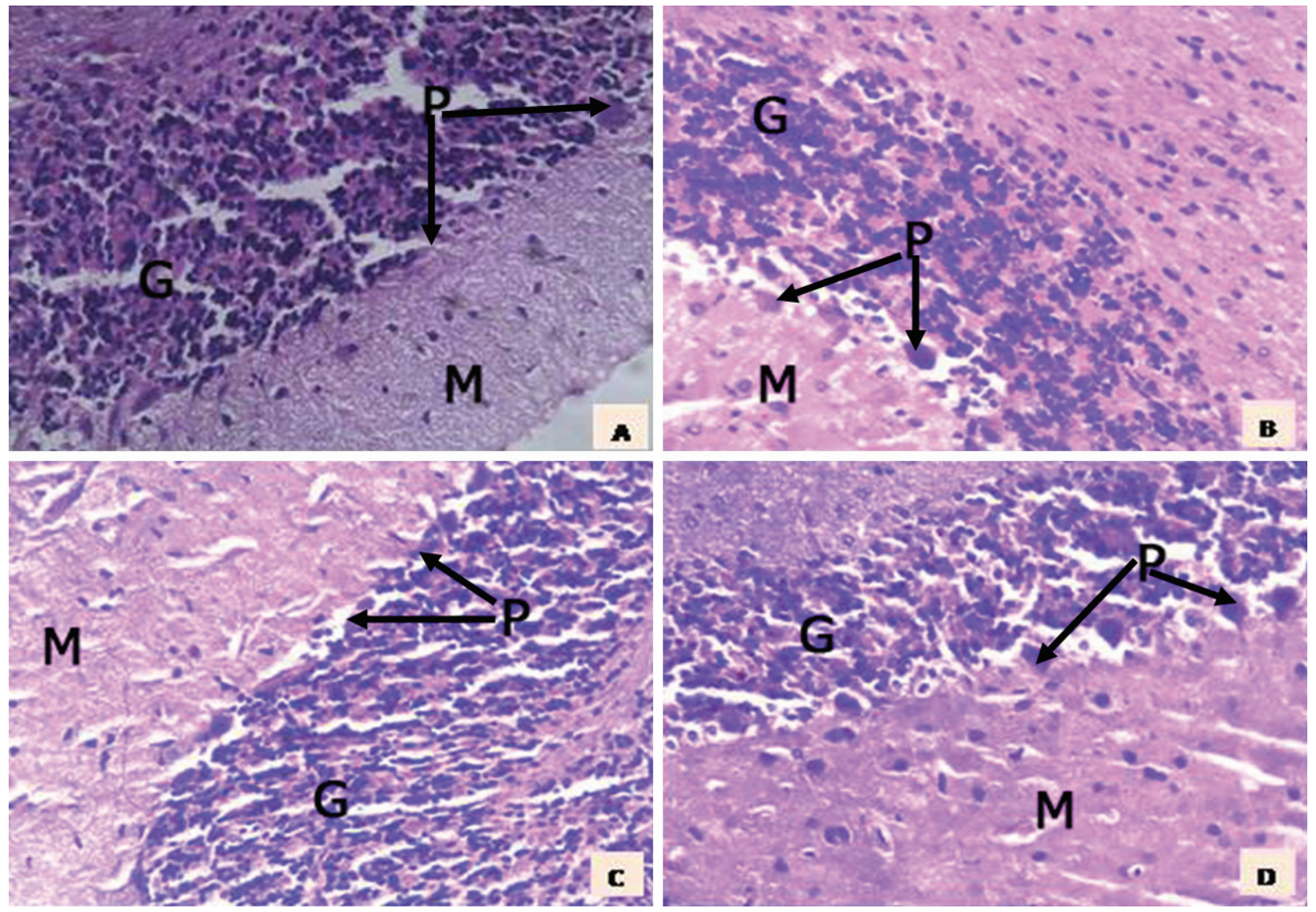

Figure 3. Light Photomicrographs of the cerebellum of Groups A, B, C and D rats. H\&E x400. M- Molecular layer; P- Purkinje cell layer; G- Granular layer. 

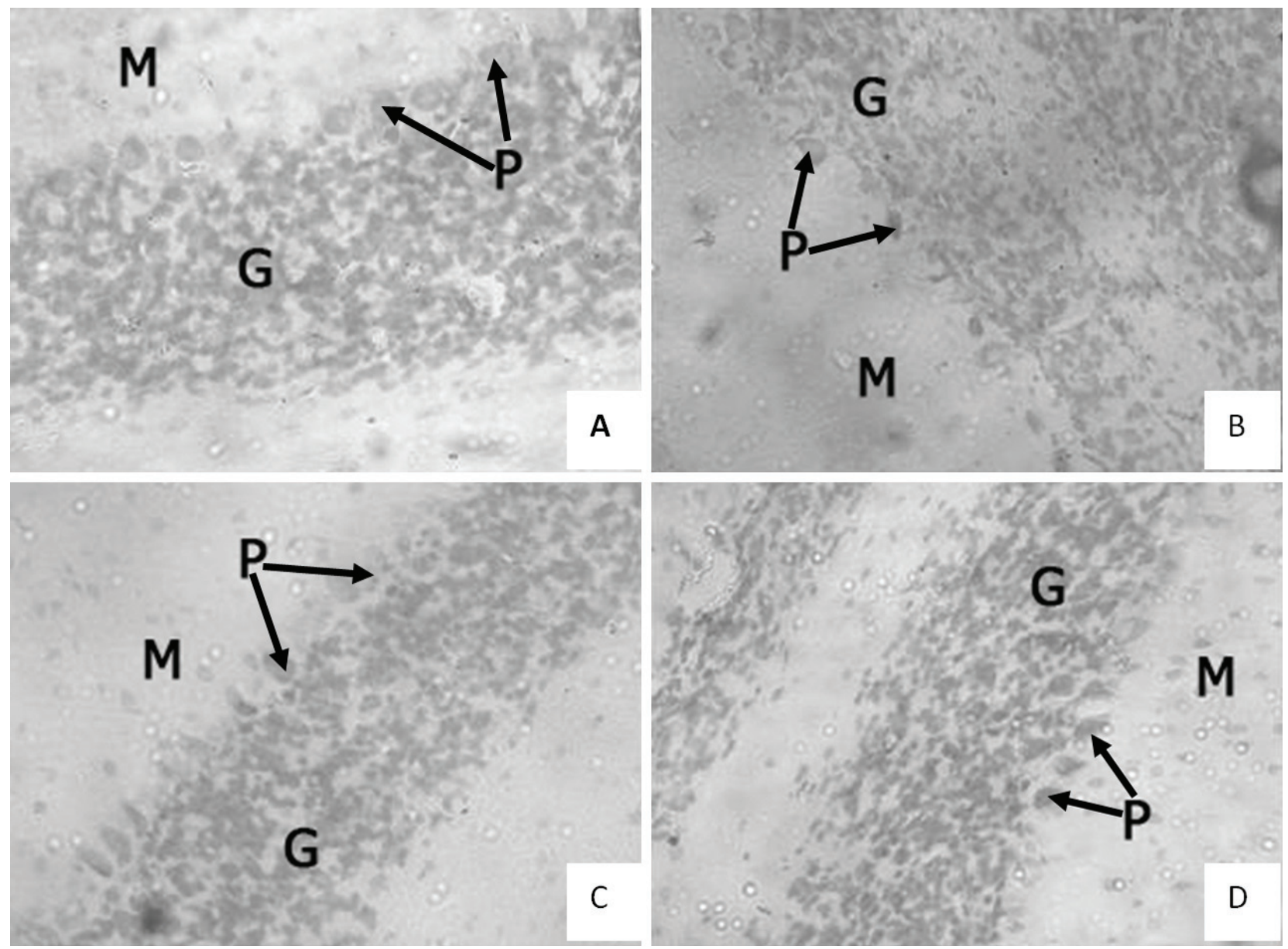

Figure 4. Light Photomicrographs of the cerebellum of Groups A, B, C and D rats. Nissl Stain x400. M- Molecular layer; P- Purkinje cell layer; G- Granular layer.

known for their potent anti-malarial activity. Arteether ${ }^{\mathrm{TM}}$ is a useful chemotherapeutic agent in the treatment of chloroquine-resistant Plasmodium falciparum malaria, without an incidence of toxicity. It has a longer half-life, and has more lipophilic properties than artemether ${ }^{\mathrm{TM}}$, which aids its accumulation in brain tissues for the treatment of cerebral malaria. Other advantages of arteether ${ }^{\mathrm{TM}}$ are its stability, compared with sodium artesunate; its biochemical breakdown does not generate methanol, as does artemether ${ }^{\mathrm{TM}}$; and it is easily formulated in oil for parenteral administration (VALECHA and TRIPATH, 1997). Pharmacodynamic studies have shown that both $\beta$-arteether ${ }^{\mathrm{TM}}$ and $\alpha / \beta$ arteether ${ }^{\mathrm{TM}}$ have comparable activity (ANIL, AMITABHA, DHANPAT et al., 2006). However, their modes of action, which include release of free radicals, have potential to cause cytotoxicity in various organs of the body (CHRIS, 2004).

Although previous studies have shown evidence of arteether $^{\mathrm{TM}}$ neurotoxicity on the brain-stem ${ }^{7}$ and superior colliculus $^{10}$, this study has shown no cyto-architectural abnormality in the retinal and cerebellum of Wistar rats treated with this agent. This finding therefore supports the speculation that the neurological symptoms reported in association with artemisinin treatment may be primarily malaria symptoms. The various adverse reactions attributed to Arteether ${ }^{\mathrm{TM}}$ may be multifactorial, which may include: (a) interaction between arteether ${ }^{\mathrm{TM}}$ and other drugs, (b) comorbidity, and/or (c) malaria itself.

In conclusion, this study has shown that therapeutic doses of arteether ${ }^{\mathrm{TM}}$ do not cause any significant cyto-pathologic change to the retina and cerebellum of Wistar rats under light microscopy.

\section{References}

ANIL, P., AMITABHA, N., DHANPAT, K., PATEL, KH., MISHRA, S. and MATHUR, PC. Efficacy and safety of $\beta$ Arteether ${ }^{\mathrm{TM}}$ and $\alpha / \beta$ Arteether ${ }^{\mathrm{TM}}$ for treatment of acute plasmodium falciparum malaria. American Journal of Tropical Medicine and Hygiene, 2006, vol. 75, n. 1, p. 139-142.

BREMAN, JG., ALILIO, MS. and MILlS A. Conquering the intolerable burden of malaria: what's new, what's needed: a summary. American Journal of Tropical Medicine and Hygiene, 2004, vol. 71, p. 1-15.

BREWER, TG., PEGgins, JO., GRATE, SJ., PETRAS, JM., LEVINE, BS., WEINA, PJ., SWEARENGEN, J., HEIFFER, MH. and SCHUSTER, BG. Neuro-toxicity in animals due to arteether and artemether. Transactions of the Royal Society of Tropical Medicine and Hygiene, 1994, vol. 88, p. 33-6. PMid:8153991. 
CHANTHAP, L., TSUYUOKA, R., NA-BANGCHANG, K., NIVANNA, N., SUKSOM, D., SOVANNARITH, T. and SOCHEAT, D. Investigation of bioavailability, pharmacokinetics and safety of new pediatric formulations of artesunate and mefloquine. Southeast Asian Journal of Tropical Medicine and Public Health, 2005, vol. 36, n. 1, p. 34-43. PMid:15906639.

CHRIS, JVB. Artemisia and Artemisinin, a story about toxicity. Uppsala reports, 2004. p. 25.

DRURY, RAB. and WALLINGTON, EA. Carleton's Histological Techniques. 4th ed. Oxford: University Press, 1980. p. 279-280.

EWEKA, AO. and ADJENE, JO. Histological studies of the effects of oral administration of artesunate on the stomach of adult Wistar rats. Internet Journal of Health, 2008b, vol. 7, n. 1, p. 1-7.

EWEKA, AO. and ADJENE, JO. Histological studies of the effects of oral administration of artesunate on the superior colliculus of adult Wistar rats. Internet Journal of Tropical Medicine, 2008a, vol. 4 , n. 2, p. 1-9.

GENOVESE, RF., NEWMAN, BD. and BREWER, TG. Behavioral and neural toxicity of the artemisinin antimalarial, arteether, but not artesunate and artelinate in rats. Pharmacology Biochemistry and Behavior, 2000, vol. 67, n. 1, p. 37-44. http://dx.doi. org/10.1016/S0091-3057(00)00309-9

HARINASUTA, T., and KARBWANG, J. Qinghaosu: A Promising antimalarial. JAMA SEA, 1994, p. 3.
HIEN, TT. An overview of the clinical use of artemisinin and its derivatives in the treatment of falciparum malaria in Vietnam. Transactions of the Royal Society of Tropical Medicine and Hygiene, 1994, vol. 88, suppl., p. 7-8. http://dx.doi. org/10.1016/0035-9203(94)90461-8

IZUNYA, AM., NWAOPARA, AO., AIGBIREM, A., ODIKE, MAC., OAIKHENA, GA. and BANKOLE, JK. Histological Effects of Oral Administration of Artesunate on the Liver in Wistar Rats. Research Journal of Applied Sciences, Engineering and Technology, 2010, vol. 2, n. 4, p. 314-318.

NONTPRASERT, A., PUKRITTAYAKAMEE, S., DONDORP, AM., CLEMENS, R., LOOAREESUWAN, S. and WHITE, NJ. Neuropathologic toxicity of artemisinin derivatives in a mouse model. American Journal of Tropical Medicine and Hygiene, 2002, vol. 67, p. 423-9. PMid:12452498.

VALECHA, N. and TRIPATH, KD. Artemisinin: current status in malaria. Indian Journal of Pharmacology, 1997, vol. 29, p. 71-75.

VAN AGTMAEL, MA., EGGELTE, TA. and VAN BOXTEL, CJ. Artemisinin drugs in the treatment of malaria; from Chinese herb to registered medication. TiPS, 1999, vol. 20, p. 1-6. PMid:10101952.

Received August 14, 2013 Accepted March 23, 2014 